\title{
INFORMAÇÕES HISTÓRICAS DO CÓDICE ATLÂNTICO DE LEONARDO DA VINCI MOBILIZADAS PARA O ENSINO DE GEOMETRIA NA EDUCAÇÃO BÁSICA
}

\author{
HISTORICAL INFORMATION FROM THE ATLANTIC CODE OF \\ LEONARDO DA VINCI MOBILIZED FOR TEACHING GEOMETRY IN \\ BASIC EDUCATION
}

\author{
Jeová Pereira Martins ${ }^{1}$ \\ Universidade Federal do Pará \\ Iran Abreu Mendes ${ }^{2}$ \\ Universidade Federal do Pará
}

\begin{abstract}
Resumo
O ensino de Geometria ocupa papel relevante dentre as pesquisas do Campo da Educação Matemática brasileira. Assim, este trabalho de cunho qualitativo tem como objetivo mobilizar informações históricas do Códice Atlântico de Leonardo da Vinci para o ensino de Geometria na Educação Básica. Trata-se de um manuscrito do século XVI que contém 1119 folhas de desenhos e anotações de Da Vinci cuja edição brasileira, em 10 volumes, contém as folhas de 1 a 602. Tomamos como recorte para este trabalho as folhas $8 \mathrm{r}$ e 36r, que estão no volume 1 da coleção, e que foram estudadas para que ficasse evidente a geometria nelas refletida como, por exemplo, elementos que remetem ao estudo de circunferência, círculo, triângulos, ângulos e segmentos de reta. Os resultados mostram que as folhas 8r e 36r contém informações históricas (MENDES, 2015), como desenhos e anotações, que remetem a temas ensinados na geometria da Educação Básica e que podem ser mobilizadas para o ensino de geometria, nesse Nível, por meio da elaboração de problematizações, nos termos de Miguel e Mendes (2010). Assim, elaboramos algumas problematizações que poderão ser tomadas como recurso pedagógico pelo professor de matemática da Educação Básica. Entendemos essas problematizações como uma proposta que poderá ser aprimorada e adaptada pelo professor para a sua realidade escolar, pois, é certo que cada escola, cada sala de aula e cada aluno são um universo particular, por isso, a proposta serve de orientação para que o professor faça as adaptações que julgar necessárias à sua efetiva implementação na sala de aula.
\end{abstract}

Palavras-chave: Leonardo da Vinci; Informações Históricas; Problematizações; Geometria da Educação Básica.

\footnotetext{
1 jeovapereira80@outlook.com

2 iamendes1@gmail.com

Número Especial - IV Seminário Cearense de História da Matemática 


\begin{abstract}
Geometry teaching occupies an important role among the researches in the field of Brazilian Mathematical Education. Thus, this qualitative work aims to mobilize historical information from Leonardo da Vinci's Atlantic Codex for the teaching of Geometry in Basic Education. It is a 16th century manuscript that contains 1119 sheets of drawings and annotations by Da Vinci, whose Brazilian edition, in 10 volumes, contains sheets 1 to 602 . We use sheets $8 \mathrm{r}$ and 36r for this work, which are in volume 1 of the collection, and that were studied so that the geometry reflected in them was evident, for example, elements that refer to the study of circumference, circle, triangles, angles and line segments. The results show that sheets $8 \mathrm{r}$ and 36r contain historical information (MENDES, 2015), such as drawings and notes, which refer to themes taught in the geometry of Basic Education and that can be mobilized for the teaching of geometry, at this Level, through the elaboration of problematizations, in the terms of Miguel and Mendes (2010). Thus, we elaborate some problematizations that could be taken as a pedagogical resource by the Basic Education mathematics teacher. We understand these problematizations as a proposal that can be improved and adapted by the teacher to his school reality, because, it is certain that each school, each classroom and each student are a particular universe, therefore, the proposal serves as a guide for the teacher makes the adaptations he deems necessary for its effective implementation in the classroom.
\end{abstract}

Keywords: Leonardo da Vinci; Historical Information; Questioning; Basic Education Geometry.

\title{
Sobre o estudo no Códice Atlântico
}

Este trabalho tem como objeto a Geometria refletida nas folhas $8 \mathrm{r}$ e $36 \mathrm{r}$ do Códice Atlântico de Leonardo da Vinci e suas relações com a geometria da Educação Básica. O referido Códice faz parte da obra de Da Vinci e reúne documentos que contém estudos e apontamentos sobre temas como matemática, astronomia, mecânica, botânica, zoologia, artes militares, geografia, química, anatomia, perspectiva, óptica, dentre outros que se materializam por meio de desenhos e anotações, aqui tomados como “informações históricas" nos termos de Mendes (2015, p. 21), que refletem temas de Geometria da Educação Básica como, por exemplo, circunferência, círculo, triângulos, ângulos e segmentos de reta (NAVONI, 2012).

Leonardo nasceu na cidade de Vinci na região da toscana na Itália do Renascimento em 15 de abril de 1452. Filho ilegítimo de Ser Piero (tabelião em Florença) com uma camponesa de Vinci chamada Caterina, foi criado pelos avós. Aos 15 anos de idade foi para Florença e ingressou no ateliê de Andrea del Verrocchio se formando como mestre-artesão 6 anos depois. A partir daí iniciou sua carreira como artista, mas 
Informações históricas do Códice Atlântico de Leonardo da Vinci mobilizadas para o ensino de Geometria na Educação Básica

Jeová Pereira Martins e Iran Abreu Mendes

também como arquiteto, engenheiro militar, inventor estudioso das ciências naturais (WHITE, 2002).

Após sua morte em 1519 suas anotações e estudos constituíam uma coleção com cerca de 13.000 páginas das quais, atualmente, conhece-se o paradeiro de mais ou menos 7000, boa parte delas reunidas em Códices que estão em bibliotecas da Itália e de outros Países (WHITE, 2002). Dentre essas coleções, está o Códice Atlântico com 1119 folhas reunidas em um único volume por Pompeo Leoni no final do século XVI que se encontra na Biblioteca Ambrosiana de Milão. Recebe o nome de Códice Atlântico por se tratar de um manuscrito (códex) em folhas no formato atlântico, ou seja, de dimensões 65cm x 44cm (SÁNCHEZ; ALMARZA, 2008a):

A versão que tomamos para este estudo foi a edição brasileira composta por 10 volumes que contém as folhas de 1 a 602, suas transcrições em língua italiana e uma descrição de cada folha em língua portuguesa. Desse total tomamos como fonte as 72 folhas do volume 1 dentre as quais selecionamos as folhas 8r e 36r para as interpretar matematicamente na busca por informações históricas que pudessem ser problematizadas e relacionadas a temas de geometria da Educação Básica.

Para selecionar as folhas em estudo (8r e 36r), inicialmente, foi feita uma leitura geral do volume 1 do Códice Atlântico de Da Vinci para identificar as folhas que tratam dos estudos de Da Vinci sobre geometria e a partir dessas folhar selecionar as que foram interpretadas. Tomamos como lente a ficha A composta por um rol de perguntas que formulamos para conduzir nosso olhar no estudo.

Quadro 1: Ficha A - Identificação dos desenhos

\begin{tabular}{|c|l|}
\hline Visão geral & $\begin{array}{l}\text { Como a folha é classificada na descrição? É uma folha sobre estudos } \\
\text { geométricos? Maquinas de guerra? Projetos arquitetônicos? }\end{array}$ \\
\hline $\begin{array}{c}\text { Visão } \\
\text { matemática }\end{array}$ & $\begin{array}{l}\text { Que matemática é refletida em cada folha observada e na sua descrição? Cálculos } \\
\text { Aritméticos? Geometria? Álgebra? }\end{array}$ \\
\hline $\begin{array}{c}\text { Visão } \\
\text { geométrica }\end{array}$ & $\begin{array}{l}\text { Que geometria pode ser relacionada aos desenhos e anotações? Ponto, reta, plano, } \\
\text { figuras geométricas planas ou espaciais? }\end{array}$ \\
\hline Detalhamento & $\begin{array}{l}\text { Todas as informações históricas da folha refletem elementos de geometria ou somente } \\
\text { uma parte? Qual seria essa parte? }\end{array}$ \\
\hline
\end{tabular}

Fonte: Elaboração dos autores.

A partir dessa leitura, dentre as 72 folhas, identificamos desenhos com potencial para nosso estudo em 18 folhas: 8, 9, 15, 26, 31, 33, 36, 40, 41, 42, 43, 44, 54, 59, 65, 
Informações históricas do Códice Atlântico de Leonardo da Vinci mobilizadas para o ensino de Geometria na Educação Básica

Jeová Pereira Martins e Iran Abreu Mendes

67, 71 e 72 e os classificamos em dois grupos, grupo 1: que recebeu o nome de desenhos geométricos, devido a classificação feita pelos autores das versões do Códice Atlântico que abordam temas como perspectiva, quadratura do círculo, teorema de Pitágoras, polígonos inscritos; e grupo 2, desenhos com potencial geométrico que tratam de temas como: estudos da luz e sombra, produção de armas e equipamentos de guerras, guindastes, moinhos de água, ou seja, desenhos cujo tema central não é a geometria, mas que têm informações que remetem a ela por tê-la como elemento fundante (SÁNCHEZ; ALMARZA, 2008a).

Esses dois grupos de desenhos foram submetidos a critérios de seleção para que se pudesse chegar a um número coerente com este trabalho e representativo dos desenhos do Códice Atlântico.

1. Potencial conceitual: Foram selecionados desenhos que remetem a temas da geometria da Educação Básica, ou seja, que podem ser conectados conceitualmente a temas de geometria previstos nos documentos oficias, livros didáticos, currículo e efetivamente ensinados nas Escolas desse Nível de Ensino como triângulos, quadriláteros, pentágonos, hexágonos, cálculo de perímetro, área e volume, sólidos geométricos, reta, ponto, plano, círculo, circunferência e etc. (BRASIL, 1997, 1998, 2018).

2. Potencial didático: Desenhos que além de terem potencial conceitual, possam ser utilizados na elaboração de atividades de ensino para os estudantes da Educação Básica, uma vez que, há desenhos que favorecem ou não a sua utilização na elaboração de atividades e outros que poderão ou não auxiliar os estudantes no estabelecimento de relações com os temas de geometria que fazem parte dos conteúdos por eles estudados.

3. Qualidade visual. Selecionamos os desenhos de maior tamanho para facilitar a visualização pelos leitores; desenhos que abordassem tema único ou temas relacionados; desenhos visíveis, ou seja, de fácil identificação, tendo em vista que, como se trata de um manuscrito do século XVI, é natural que alguns desenhos sejam de difícil identificação e visualização devido ao desgaste natural.

4. Coerência entre a leitura do desenho e a descrição: Em alguns desenhos a descrição não é suficiente para dizer do que ele trata, pois observamos elementos nos desenhos que não foram contemplados na descrição. Por outro lado, há descrições que 
Informações históricas do Códice Atlântico de Leonardo da Vinci mobilizadas para o ensino de Geometria na Educação Básica

Jeová Pereira Martins e Iran Abreu Mendes

tratam de temas de geometria que nossa observação não foi capaz de identificar no desenho;

Enfatizamos que os desenhos do Códice Atlântico têm valor imensurável como patrimônio sociocultural e científico e poderão ser objeto de pesquisas com outros focos e objetivos, porém, para este trabalho, a partir dos critérios estabelecidos, selecionamos as folhas $8 \mathrm{r}$ representando os desenhos do grupo 2 e 36r que faz parte do grupo 1 que foram interpretados no tópico seguinte.

\section{A interpretação matemática das folhas 36r e 8r}

A interpretação das folhas selecionadas foi feita segundo a ficha B. O objetivo dessa interpretação foi evidenciar as informações históricas presentes nas folhas, desenhos e anotações, que remetem a temas de geometria ensinados na Educação Básica. Tais informações são a base para as problematizações elaboradas.

Quadro 2: Ficha B - interpretação das folhas do Códice Atlântico

\begin{tabular}{|c|l|}
\hline $\begin{array}{c}\text { Caracterização } \\
\text { da folha }\end{array}$ & $\begin{array}{l}\text { Descrição da folha, tomando-se como referência e descrição contida } \\
\text { no Códice Atlântico. }\end{array}$ \\
\hline Detalhe & $\begin{array}{l}\text { Qual o detalhe da folha selecionada contém informações históricas } \\
\text { que refletem temas ensinados na Educação Básica? Esse detalhe receberá um } \\
\text { tratamento (marcações com setas, números, letras e etc.) ou terá seu desenho } \\
\text { reelaborado para auxiliar na sua interpretação. }\end{array}$ \\
\hline $\begin{array}{c}\text { Interpretação } \\
\text { do detalhe }\end{array}$ & $\begin{array}{l}\text { A interpretação do detalhe exprime uma nova descrição, apoiada na } \\
\text { descrição já contida no Códice, mas incrementada com outros elementos da } \\
\text { geometria da Educação Básica. }\end{array}$ \\
\hline $\begin{array}{c}\text { Potencial } \\
\text { conceitual }\end{array}$ & $\begin{array}{l}\text { Quais as possíveis relações conceituais entre as informações históricas das folhas } \\
\text { Leonardo da Vinci e a geometria da Educação Básica? }\end{array}$ \\
\hline $\begin{array}{c}\text { Potencial } \\
\text { didático }\end{array}$ & $\begin{array}{l}\text { Qual o potencial didático dos desenhos do Códice Atlântico para o } \\
\text { ensino de geometria na Educação Básica? } \\
\text { A partir das relações do desenho com tópicos da geometria da Educação Básica, } \\
\text { pode-se, então, problematizar essas informações para o ensino. }\end{array}$ \\
\hline $\begin{array}{c}\text { Orientações ao } \\
\text { professor }\end{array}$ & $\begin{array}{l}\text { Que esclarecimentos, sobre o estudo feito com o desenho do Códice } \\
\text { Atlântico, poderão auxiliar o professor na implementação da proposta em suas aulas } \\
\text { de matemática? }\end{array}$ \\
\hline
\end{tabular}

Fonte: elaboração dos autores.

A folha 36r (figura 1) contém um grupo de desenhos que remetem a geometria. São duas pirâmides decompostas em pirâmides menores, círculos e lúnulas. Na metade inferior, um grupo de desenhos mecânicos, como rodas dentadas (engrenagens) entre 
Informações históricas do Códice Atlântico de Leonardo da Vinci mobilizadas para o ensino de Geometria na Educação Básica

Jeová Pereira Martins e Iran Abreu Mendes

os quais encontram-se algumas operações aritméticas com destaque para os cálculos do quadrado de 25 e de 36.

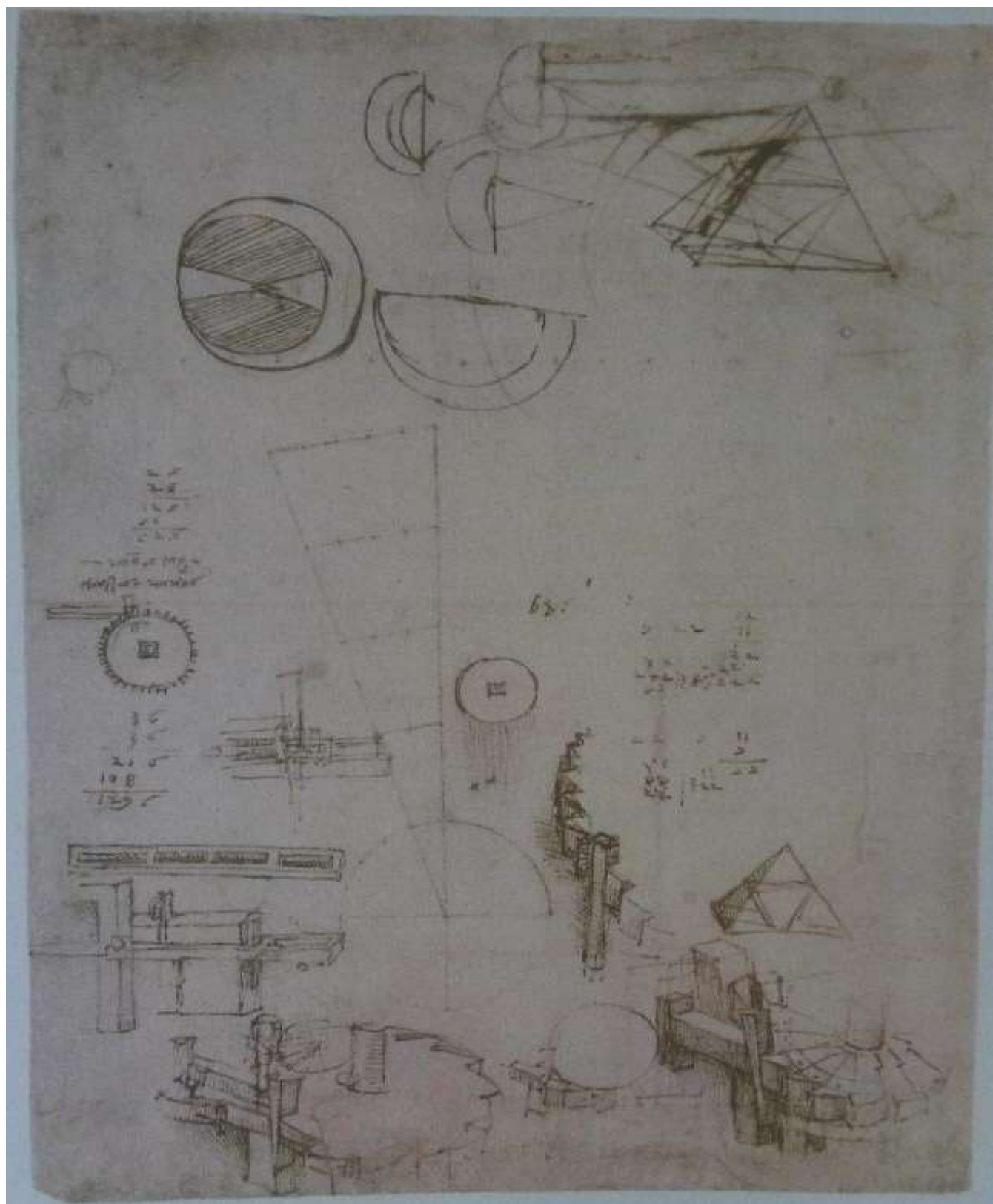

Figura 1 - Folha $35 \mathrm{r}$

Fonte: Sáncheze Almarza (2008a, p. 103).

Na metade inferior da folha, quase no centro, traçado com régua e compasso, um triângulo isóscele com um de seus vértices no centro de um círculo. Pelo desenho é possível verificar que há uma relação entre o raio do círculo e os lados iguais do triângulo. Na figura 2 destacamos o desenho em questão e inserimos marcações (letras) para indicar pontos importantes deste (SÁNCHEZ; ALMARZA, 2008a). 
Informações históricas do Códice Atlântico de Leonardo da Vinci mobilizadas para o ensino de Geometria na Educação Básica

Jeová Pereira Martins e Iran Abreu Mendes

O desenho do detalhe é visto no reto e no verso da folha, mas só é mencionado na descrição do verso da folha 36. Trata-se e um triângulo isósceles (ABC) cujos lados congruentes (AC e $\mathrm{BC}$ ) medem 5 vezes a medida do raio da circunferênca. Um de seus vértices $(\mathrm{C})$ coincide com o centro da circunferência e o ângulo referente ao vértice $\mathrm{C}$ é de $18^{\circ}$, pois o arco $\mathrm{KN}$, que mede $90^{\circ}$, possui marcações que o divide em cinco partes iguais.

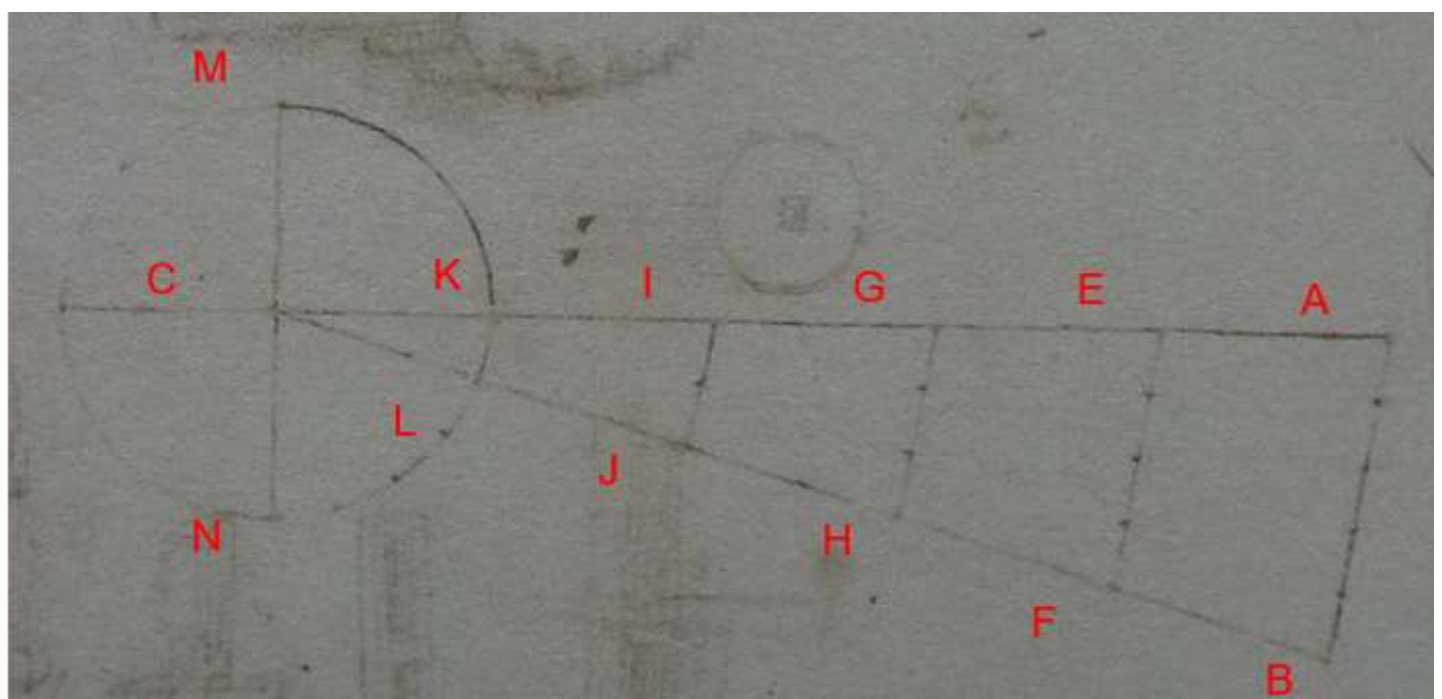

Figura 2 - Triângulo isósceles e círculo Fonte: Sáncheze Almarza (2008a, p. 103).

As relações conceituais com a geometria da Educação Básica podem ser estabelecidas tomando-se isoladamente uma das figuras da folha (triângulo ou circunferência) e as relacionando a tópicos de geometria como os da geometria plana que faz parte do currículo do Ensino Fundamental, mas que é mobilizada, também, no Ensino Médio quando se estuda, por exemplo, os sólidos geométricos.

$\mathrm{O}$ triângulo $\mathrm{ABC}$ remete aos tópicos: 1) classificação dos triângulos quanto a medida dos lados (equilátero, isósceles ou escaleno); 2) soma dos ângulos internos do triângulo; 3) área do triângulo; 4) Semelhança entre triângulos. Já a circunferência permite explorar os tópicos: 5) Raio, diâmetro, centro, cordas, área; 6) definição de círculo, área do círculo, setor circular, área do setor, área da coroa circular (BRASIL, 1997, 1998, 2018).

Além dos temas de geometria listados, é possível explorar, ainda, a relação que entre o raio da circunferência e o lado do triângulo o que pode ser objeto de estudo pelos estudantes que tiverem contato com o desenho. 
Informações históricas do Códice Atlântico de Leonardo da Vinci mobilizadas para o ensino de Geometria na Educação Básica

Jeová Pereira Martins e Iran Abreu Mendes

As relações do desenho com o ensino de geometria podem ser estabelecidas por meio de problematizações que mobilizem os tópicos listados no potencial conceitual. Essas problematizações se materializam em uma série de questionamentos que devem ser formulados intencionalmente pelo professor para levar o estudante a estabelecer conexões das informações históricas do Códice Atlântico com os temas de geometria por ele estudados (MIGUEL; MENDES, 2010).

\section{Problematizações sobre a circunferência}

1) Considere a circunferência contida no desenho de Leonardo e os elementos que ela contém! Como se chamam os segmentos MN e MC?

2) Que relação é possível estabelecer entre as medidas desses segmentos?

3) Que ponto representa o centro da circunferência?

4) Considere que o segmento MC mede 2u.m. A partir dessa medida, é possível calcular a medida de $\mathrm{MN}$ ?

5) Qual seria o procedimento para esse cálculo e qual o a medida de MN?

6) Tomando-se as medidas de $\mathrm{MC}$ e MN, calcule o comprimento da circunferência e a área do círculo em questão!

\section{Problematizações sobre o triângulo}

1) Perceba que no desenho de Leonardo em destaque, há um triângulo $\mathrm{ABC}$ ! Além do triângulo $\mathrm{ABC}$, é possível identificar outros triângulos no desenho? Quais?

2) Esses triângulos são semelhantes? São congruentes? Justifique sua reposta!

3) Perceba que no desenho de Leonardo há alguns segmentos de reta. Segundo a descrição do desenho o seguimento AC é 5 vezes o segmento CK. Partindo dessa afirmação e considerando todos os segmentos que dividem o segmento AC, que relações é possível estabelecer entre AC e os demais seguimentos que o dividem?

Os questionamentos formulados são sugestões que poderão ser aprimorados para atender aos objetivos de ensino do professor que poderá elaborar outras atividades com base nos desenhos de Leonardo da Vinci. As atividades poderão ser estruturadas de forma que o estudante possa ser levado a fazer uma investigação sobre o tema na busca por possíveis respostas. A intenção é que as atividades não sejam uma lista de exercício a serem resolvidos, mas um momento de movimentação dos estudantes em torno de um 
Informações históricas do Códice Atlântico de Leonardo da Vinci mobilizadas para o ensino de Geometria na Educação Básica

Jeová Pereira Martins e Iran Abreu Mendes

objetivo. Os resultados obtidos pelos estudantes na investigação poderão, ainda, ser socializados na sua turma e até com outros estudantes da Escola.

A folha $8 \mathrm{r}$ faz parte do grupo 2, dos desenhos com potencial geométrico, pois apresenta, acima, uma roda de moinho de dez braças de diâmetro, movido por água, com anotação. Abaixo, outra roda de moinho tripartite, com anotação. À esquerda, detalhes da roda e das pás, sem escritos (SÁNCHEZ; ALMARZA, 2008a).

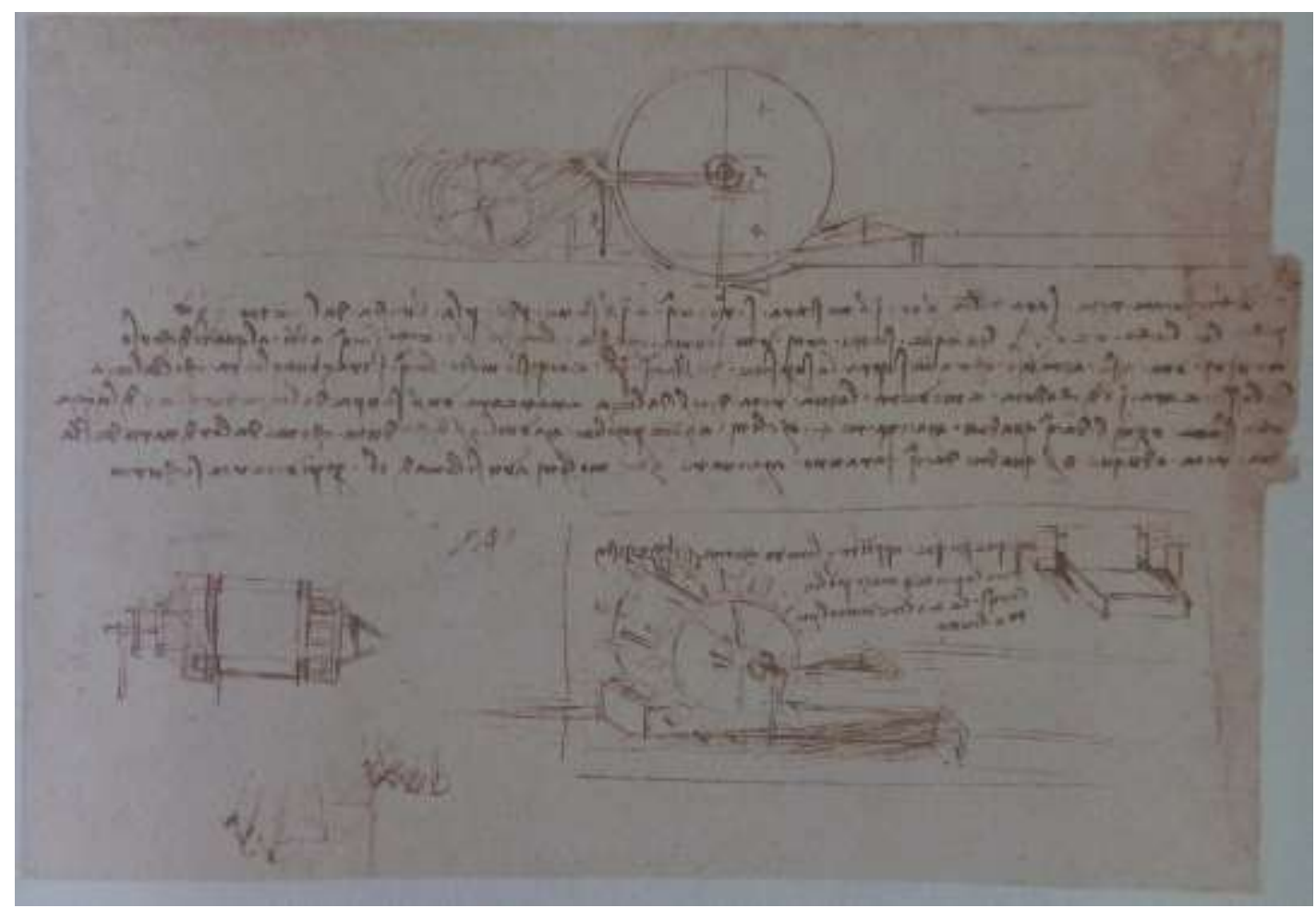

Figura 3 - Folha $8 \mathrm{r}$

Fonte: Sánchez e Almarza (2008a, p. 39)

O detalhe do desenho que selecionamos (figura 4) é o primeiro esquema de maionho no alto da folha. A interpretação do detalhe exprime uma leitura do desenho original tendo em vista que a nosso ver o sistema acima é composto por duas rodas (circunferências) e um triângulo. Esse sistema de rodas que movimentaria um moinho funcionaria da seguinte maneira: a roda 1 está submersa cerca de uma braça (até o ponto $\mathrm{B}$ em um rio corrente. $\mathrm{O}$ fluxo de água gira a roda 1 que eleva a água (por meio de um sistema de conchas) até o ponto $\mathrm{C}$ que está e 3 braças de altura em relação ao ponto E. A água, então desliza por uma rampa que vai de $\mathrm{C}$ a $\mathrm{D}$ e seu fluxo faz girar a roda 3 por meio de um sistema de pás fixas a ela. 
Informações históricas do Códice Atlântico de Leonardo da Vinci mobilizadas para o ensino de Geometria na Educação Básica

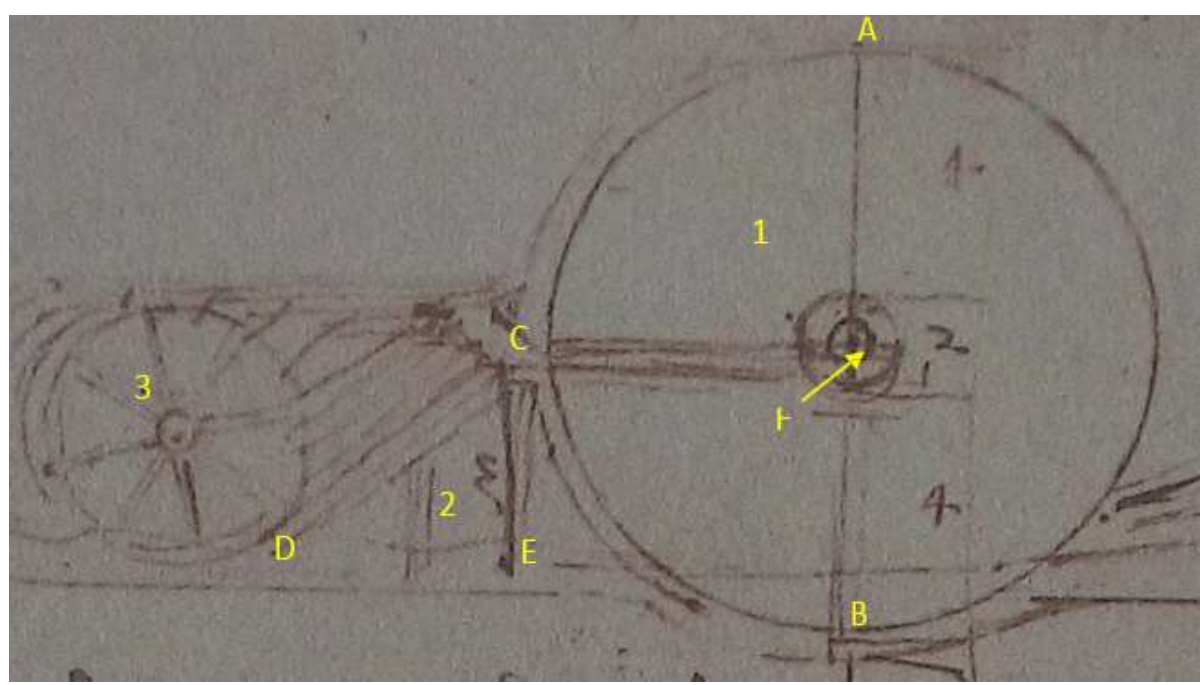

Figura 4 - Moinho de água

Fonte: Sánchez e Almarza (2008a, p. 39).

Para que o potencial geométrico do desenho fosse reforçado, fizemos um desenho semelhante (figura 5) que remete a figuras geométricas planas, quais sejam, duas circunferências (1 e 3) e um triângulo retângulo (CDE). A circunferência 1 tem diâmetro 10 braças (conforme a transcrição do Códice) e a circunferência 2 tem diâmetro menor. A circunferência maior tem um "buraco" no centro $(F)$ que pode ser representado por uma circunferência de diâmetro duas braças. O detalhe em questão está melhor representado na figura 5 que foi construído com vistas à conexão com a matemática da Escola Básica.

Sobre a circunferência 3 foram traçados quatro diâmetros que formam um ângulo de $45^{\circ}$ entre si, ou seja, os diâmetros dividem a circunferência em $8 \operatorname{arcos}$ de $45^{\circ}$ cada um e ainda em setores circulares cujo ângulo central é de $45^{\circ}$. Essa circunferência tem diâmetro 4 braças (por construção), portanto raio 2. O triangulo CDE é retângulo e um de seus catetos mede 3 braças.

A circunferência 1 de centro $F$ possui duas circunferências concêntricas a ela, uma de diâmetro duas braças e outro de diâmetro desconhecido. A figura 3 possui alguns seguimentos de reta dos quais destaca-se os segmentos $\mathrm{x}, \mathrm{y}$ e $\mathrm{z} \cdot \mathrm{y}=\mathrm{z}=1$ e $\mathrm{x}=3$, os quais podem ser relacionados aos diâmetros e raios das circunferências aos catetos do triângulo retângulo. 


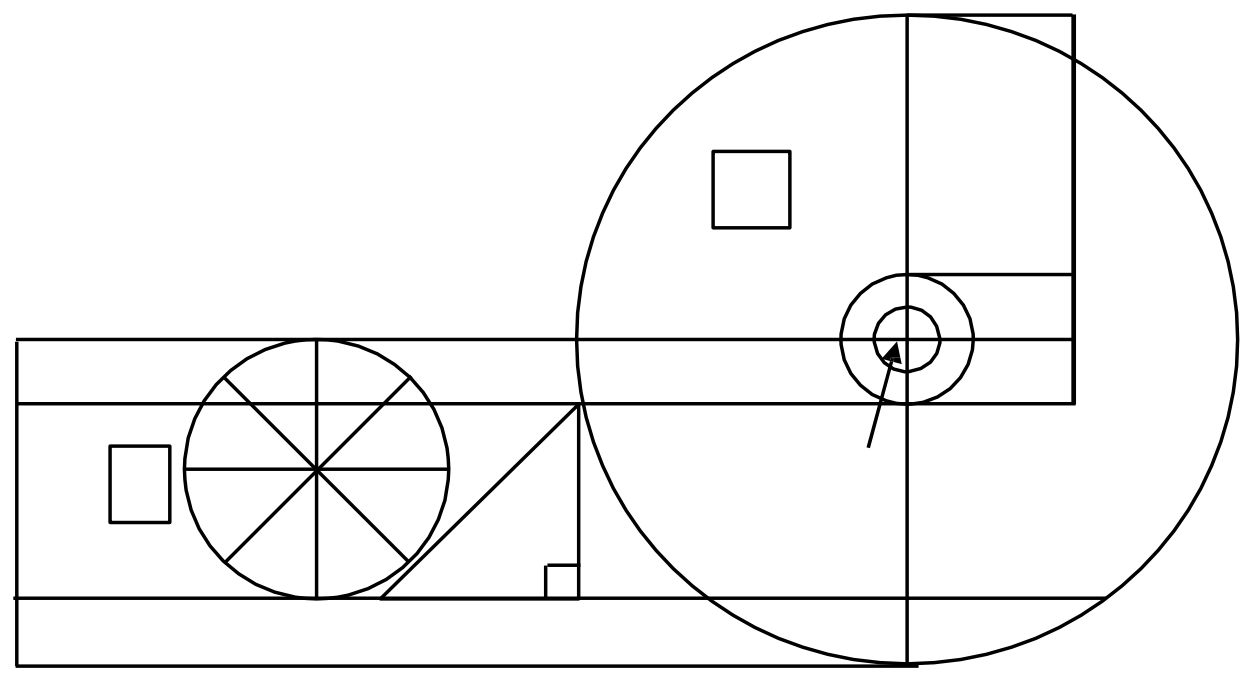

Figura 5 - Esquema do moinho

Fonte: Adaptado de Sánchez e Almarza (2008a).

Os desenhos da figura 5 se conectam a alguns tópicos da matemática da Escola Básica que se inserem na geometria plana e analítica. Dentre esses tópicos destacamos: 1) Circunferência: definição de circunferência, centro, raio, diâmetro, corda, arco, ângulo, comprimento da circunferência, equação da circunferência (tópicos do EF e EM); 2) Círculo: definição de círculo, área do círculo, setor circular, área do setor, área da coroa circular; 3) Triângulo: triângulo isósceles, triângulo equilátero, triângulo escaleno, triângulo retângulo, soma dos ângulos internos do triângulo, teorema de Pitágoras (BRASIL, 1997, 1998, 2018).

A partir da conexão feita com tópicos da matemática da educação Básica, podese, então, problematizar essas informações para o ensino. As questões a seguir são exemplos dessa problematização que poderá favorecer o ensino dos tópicos que elencamos anteriormente no Nível Fundamental e Médio.

\section{Problematizações sobre a circunferência 1}

1) Qual o diâmetro e o raio da circunferência? Que relação há entre diâmetro e raio? Quantos diâmetros você visualiza na circunferência?

2) Considerando que o ângulo formado por dois diâmetros consecutivos é o mesmo em todos os casos, quando mede cada um desses ângulos?

3) Qual o comprimento do arco delimitado por dois raios consecutivos?

4) Qual a área do círculo delimitado pela circunferência em estudo?

5) Quantos setores circulares os diâmetros determinam? 
Informações históricas do Códice Atlântico de Leonardo da Vinci mobilizadas para o ensino de Geometria na Educação Básica

Jeová Pereira Martins e Iran Abreu Mendes

6) Tem-se no desenho três circunferências concêntricas (centro F) cujas medidas estão em braças. Considere que uma das duas circunferências menores têm diâmetro duas braças e a outra uma braça. (tome uma braça equivalente a 2,20 metros e y = z). Determine, em metros, o raio e o diâmetro de cada uma das três circunferências em questão!

7) Determine a razão entre o raio e o diâmetro de cada circunferência! O que você conclui a partir das razões encontradas?

8) Qual a área do círculo maior? Qual o comprimento da circunferência de diâmetro maior?

9) Considere que as três circunferências concêntricas têm centro $F(0,0)$. Determine as equações de cada uma delas.

\section{Problematizações sobre o triângulo CDE}

1) Supondo-se que o triângulo é retângulo é isósceles, responda: Como você procederia para determinar o outro cateto e a hipotenusa desse triângulo? Quanto mede o outro cateto e a hipotenusa?

2) Caracterize cateto! Caracterize hipotenusa! Caracterize triângulo isósceles! Qual a classificação de um triangulo quanto a medida de seus lados?

3) Sabe-se que um dos ângulos internos do triângulo mede $90^{\circ}$, assim, qual é medida dos outros dois ângulos internos?

4) Que relação entre as medidas dos ângulos internos do triângulo você faria?

Sobre a circunferência 1 .

Fizemos um estudo da folha 8r do Códice Atlântico para mostrar o seu potencial conceitual e didático. Nossa intenção é fornecer elementos que tornem possível o estabelecimento de relações pelo estudante entre a geometria do Códice Atlântico e os temas de geometria da Educação Básica. Além disso, o professor de Matemática desse Nível de Ensino, poderá reformular as ideias aqui apresentadas para tender as demandas do contexto no qual seus alunos se inserem e os objetivos de aprendizagem a serem alcançados. 
Informações históricas do Códice Atlântico de Leonardo da Vinci mobilizadas para o ensino de Geometria na Educação Básica

Jeová Pereira Martins e Iran Abreu Mendes

\section{Considerações}

O estudo feito nas folhas 8r e 36r permitiu verificar que os desenhos e anotações remetem a entes ou figuras geométricas como segmentos de reta, triângulos, quadrados, retângulos, dentre outros, que possibilitam o estabelecimento de relações com tópicos de geometria ensinados na Educação Básica. Isso foi materializado por meio de problematizações das informações históricas presentes nas folhas do Códice Atlântico mencionadas.

Como demostramos, o potencial conceitual e didático pode ser detectado por meio do tratamento dos desenhos por um método que envolve descrição e análise. Esse tratamento foi feito, por meio de uma matriz de leitura dos desenhos (Ficha B) que permitiu o estabelecimento de relações dos desenhos e anotações de Leonardo da Vinci e de suas partes com a geometria da Educação Básica.

Consideramos que o estudo feito no volume 1 do Códice Atlântico nos dá possibilidade de amplia-lo para os outros volumes da coleção pois concluímos que o volume 1 tem potencial conceitual e didático para o ensino de Geometria na Educação Básica, que podem ser explorados pelo professor por meio da problematização criativa dos desenhos e anotações como forma de mobilizar as informações contidas nas folhas, para a sala de aula de matemática desse Nível de ensino.

\section{Referências}

BAGNI, G. T.; D’AMORE, B. Leonardo e a matemática - São Paulo, SP. Editora Livraria da Física, 2012.

BARROS, José D’Assunção. Os conceitos: Seus usos nas ciências humanas Petrópolis, RJ: Vozes, 2016.

BRASIL. Base Nacional Comum Curricular: Ensino Fundamental. Brasília: MEC/Secretaria de Educação Básica, 2018.

BRASIL. Ministério da Educação. Parâmetros Curriculares Nacionais para o Ensino de Matemática de $1^{\text {a }}$ a $4^{\text {a }}$ séries, PCN. 1997.

BRASIL. Ministério da Educação. Parâmetros Curriculares Nacionais para o Ensino de Matemática de $5^{\mathrm{a}}$ a $8^{\mathrm{a}}$ séries, PCN. 1998.

MENDES, I. A. História da matemática no ensino: entre trajetórias profissionais epistemologias e pesquisas. São Paulo: Editora Livraria da Física, 2015. 
MENDES, I. A. Investigação Histórica no Ensino da Matemática. Rio de Janeiro: Editora Ciência Moderna, 2009.

MIGUEL, Antonio; MENDES, Iran Abreu. Mobilizing histories in mathematics teacher education: memories, social practices, and discursive games. In: ZDM Mathematics Education. v. 42. p. $381-392,2010$.

NAVONI, M. Leonardo da Vinci y los secretos del Códice Atlántico. Tradução Eva María Cantenys Félez e Antonio Díaz Pérez. Art Blume, S. L. Barcelona, 2012.

SÁNCHEZ, J. L.; ALMARZA, M. O Códice Atlântico de Leonardo da Vinci (vol. 3) (Coleção O códice Atlântico de Leonardo da Vinci). Barcelona: Fólio, 2008

SÁNCHEZ, J. L.; ALMARZA, M. O Códice Atlântico de Leonardo da Vinci (vol. 1) (Coleção O códice Atlântico de Leonardo da Vinci). Barcelona: Fólio, 2008.

SÁNCHEZ, J. L.; ALMARZA, M. O Códice Atlântico de Leonardo da Vinci (vol. 2) (Coleção O códice Atlântico de Leonardo da Vinci). Barcelona: Fólio, 2008

WHITE, M. Leonardo o primeiro cientista. 4 ed. - Rio de Janeiro, RJ. Record, 2002. 